\title{
AS ATIVIDADES LÚDICAS COMO FERRAMENTA DE ENSINO DE LÍNGUA ESTRANGEIRA NA EDUCAÇÃO INFANTIL
}

\author{
SANDRA SIMONE DUQUEVIZ LUDERO ${ }^{1}$ \\ Centro Educacional Loni Emmendoerfer \\ AMANDA NOVELETTO ${ }^{2}$ \\ Centro Educacional Loni Emmendoerfer
}

\begin{abstract}
RESUMO: Compreendendo a Língua Estrangeira (LE) como formadora da cultura e do indivíduo, seu ensino revela-se significativo para a sociedade, de maneira ampla, mas também valoroso na Educação Infantil (EI). Neste sentido, propõe-se aqui analisar o uso das atividades lúdicas como uma das ferramentas no Ensino de Língua Estrangeira nos primeiros anos educacionais. Com este estudo, busca-se refletir sobre o impacto e a funcionalidade do uso de atividades lúdicas em Língua Estrangeira no desenvolvimento e no processo das aulas de LE com as crianças. Esta pesquisa investigou, por meio de uma pesquisa bibliográfica, a atividade lúdica como um possível instrumento pedagógico que estreita a relação entre os alunos e a LE com seu caráter entusiástico, atraente e também por fazer parte do cotidiano da criança. Por fim, a conclusão obtida com este estudo foi a legitimidade do uso da atividade lúdica no ensino de LE, assim como a relevância dos resultados apresentados, que levem ao avanço do estudo desta área da educação.
\end{abstract}

PALAVRAS-CHAVE: Língua Estrangeira; Educação Infantil; Atividade lúdica.

ABSTRACT: Understanding the Foreing Language (FL) as a form of culture and individual, indivíduo, its teaching proves to be meaningful for society, in a broad way, but also valuable in Early Childhood Education. In this sense, it is proposed here to analyze the use of play activities as one of the tools in teaching a Foreign Language in first educational years. This study aims to reflect about the impact and funcionality of the use of play activities in Foreingn Language in the development and in the processo $f$ teaching Foreingn Language for children. This research investigated, through a bibliographical research, the play activity as a possible pedagogical instrument that narrows the realtion between the students and the Foreign Language with its enthussiastic character, attractive and also for being part of children daily life. Finally, the conclusion obtained with this study was the legitimacy of the use of play activities in Foreing Language, as well as the relevance of the presented results, which lead to the advancement of the study of this education area.

KEYWORDS: Foreign Language; Childhood Education; Play activities.

\section{Introdução}

O ensino de Língua Estrangeira (LE) para as crianças revela-se, mesmo atualmente, um desafio. Ao incumbir-se dele e dispor-se ao trabalho com a EI, se faz necessário levar em conta todas as especificidades elas possuem. Como sugerem autores que se debruçaram sobre o assunto (GUEBERT E TRAUTWEIN, 2007) fatores como a maturidade cognitiva dos

\footnotetext{
${ }^{1}$ Professora pós-graduada em ciência pelo Instituto Federal (IFSC). Graduada em Física e Ciência pelo Instituto Federal (IFSC), graduada em Matemática pela Universidade Paulista (UNIP) e aluna em Letras - Língua Portuguesa e Inglês.

${ }^{2}$ Professora pós-graduanda em Educação Infantil e Primeiros Anos do Ensino Fundamental pela UniCesumar. Graduada em Letras - Língua e Literatura Francesa pela Universidade Federal de Santa Catarina (UFSC).
} 
alunos, as relações sociais que se formam nesta idade e seus desenvolvimentos orgânicos, devem ser considerados para encaminhar-se pedagogicamente e adequar-se às características da Educação Infantil.

$\mathrm{Na}$ busca de aparatos e instrumentos que atendam as necessidades de um ensino de LE lúdico para a $\mathrm{EI}$, depara-se com o artifício da música, regularmente utilizada por professores de LE em suas variadas aulas com outros grupos distintos (adolescentes, adultos, etc.), brincadeiras, jogos, histórias e dramatizações.

Nos próximos tópicos apresentar-se-á estudos que defendem principalmente o uso da música para o ensino de LE neste contexto, e analisar-se-á a correlação entre eles com relatos de experiências em sala de aula. Este artigo será assim subdividido: em um primeiro momento serão abordadas as dificuldades do ensino de LE na EI, em um segundo momento serão analisados os benefícios do uso da música da EI, posteriormente será avaliada a eficácia do uso da música no ensino da LE na EI, encerrando com as considerações finais.

\section{O ensino de língua estrangeira na educação infantil}

Quando se trabalha com o ensino de Língua Estrangeira com turmas da Educação Infantil, logo se depara com dificuldades que surgem com o contato destes. Segundo as autoras Guebert e Trautwein (2007, p. 1369), a criança, principalmente a partir dos dois anos, necessita de um meio concreto de aprendizagem que possibilite o seu processo de assimilação e acomodação da informação. O professor de LE leva para seus alunos de Educação Infantil informações novas que se tornam, por vezes, abstratas e entram em contradição com seus conhecimentos prévios. Como estes alunos devem encarar o informe de outra palavra para qual eles já conheciam o nome? Como explicar-lhes que existem outras línguas, que são diferentes da deles, e que elas são faladas em outros lugares, sabendo a noção limitada de espaço que eles possuem? Tais questões são feitas tanto pelo professor como, intuitivamente, pelas crianças. Os alunos da Educação Infantil podem, então, questionar-se da funcionalidade do aprendizado desta segunda língua.

Com esta breve análise, já se pode constatar os pontos de dificuldade que se apresentam dentro do ensino de LE na Educação Infantil. Em contrapartida, Guebert e Trautwein (2007), sugerem que a primeira língua se figura como algo mecânico, diferentemente do processo de construção da segunda língua, a LE. Sendo assim, o ensino de LE é:

Um processo demorado, sistemático, seqüencial e que deve considerar a etapa do desenvolvimento cognitivo para que esta construção seja funcional para que o aluno sinta-se a vontade com estas novas expressões e entenda que uma língua não restringe a outra, pelo contrário a complementa. (GUEBERT; TRAUTWEIN, 2007, p. 1369). 
Assim considerando o ensino de LE edificador para o aluno de Educação Infantil, também cabe inferir que trabalhar com uma diferente forma de linguagem, neste caso uma nova língua, possibilita a criança a se desenvolver cognitivamente e afetivamente, encaminhando-a, dessa maneira, a um desenvolvimento integral.

Guebert e Trautwein (2007) também defendem que, com o contato sucessivo com a LE, a criança começa a criar afeição e prazer por seu ensino e busca, de forma autônoma, funcionalidades para esta. Desta forma, o professor deve estar constantemente atento aos conteúdos que levará para a sala de aula para que eles possam ter relação com os interesses dos alunos. Quanto a esse ponto, também se acredita que a exposição a novas informações e a ampliação do conhecimento lingüístico produza uma reconstrução dos gostos e comportamentos. Os alunos podem, por meio da apresentação da LE, desenvolver e descobrir novos interesses. Assim com Bueno e Leal (2003, p. 55) afirmam "Como elemento de autoconhecimento e de conhecimento do outro, o estudo e aprendizagem de uma língua estrangeira contribui para o aperfeiçoamento das relações pessoais e sociais". As autoras Guebert e Trautwein (2007, p. 1370) alegam que, desta forma, a LE se torna "[...] um elemento de construção social e interação cultural que passa a ser importante ara a formação futura da criança".

Visto as dificuldades e os benefícios deste ensino no ambiente da Educação Infantil, o professor indaga agora qual a metodologia que deverá ser empregada para responder aos seus objetivos com o grupo que trabalha. Tendo em conta que, ao se referir à língua materna, a criança constrói gradativamente seu conhecimento por meio de estímulos do meio, onde a língua é falada e compreendida por todos ao seu redor (ROSIN; TINOCO, 1998). As autoras Guebert e Trautwein (2007) ressaltam que no caso da LE, os estímulos partem do professor, principalmente neste nível de ensino, que se esforça para que a informação que fornece seja internalizada, compreendida e posteriormente utilizada por seus alunos. Este esforço didático está diretamente ligado com a motivação, podendo por vezes sem compreendido como ela própria.

O fator motivação é listado como elemento extrínseco da aprendizagem de uma LE pelas autoras Guebert e Trautwein (2007, p. 1372):

A motivação vinda do professor deve gerar no aluno curiosidade, interesse e desejo de aprender para que este perceba a funcionalidade do conteúdo desenvolvido. O professor tem como seu aliado neste processo diferentes metodologias bem como o próprio aluno que é o foco do seu trabalho. O professor deve estar atento às respostas do aluno para que possa, quando necessário, se adaptar às diferentes situações de aprendizagem.

Desta forma, percebe-se que a motivação deve permear todas as aulas de LE e, principalmente, seu planejamento. Ela deve servir como mediadora para as escolhas do professor, suas metodologias e conteúdos. Este deve levar em conta as respostas de suas investidas, sabendo que estímulos ministrados possuem respostas, estas geralmente instantâneas. Segundo Guebert e Trautwein (2007), o aluno, nesta situação, possui o papel de 
avaliador da metodologia e estímulos fornecidos pelo professor. Se o aluno se mostrar desinteressado, o professor precisa mudar sua didática para que a turma demonstre encontrar sentido no conteúdo apresentado.

Segundo Bueno e Leal (2003), para um aluno tão jovem, a questão da motivação e da metodologia de seu professor não é evidente durante a sua aula de LE. Mesmo sem pensarem sobre isso, aliás, o processo de aprendizado nesta época é mais sensorial do que reflexivo, as crianças respondem diretamente a esses dois fatores. A motivação para elas deve estar presente por meio de jogos e músicas, ou seja, atividades lúdicas. O professor de LE não pode esquecer-se de atender às diretrizes nacionais deste nível de ensino, a Educação Infantil, que enfatiza e prioriza a brincadeira e a descoberta do mundo para a formação integral da criança. De acordo com o texto das Diretrizes Curriculares Nacionais para a Educação Infantil (BRASIL, 2010, p. 27, grifos do original):

As práticas pedagógicas que compõem a proposta curricular da Educação Infantil devem ter como eixos norteadores as interações e a brincadeira e garantir experiências que:

- Promovam o conhecimento de si e do mundo por meio da ampliação de experiências sensoriais, expressivas, corporais que possibilitem movimentação ampla, expressão da individualidade e respeito pelos ritmos e desejos da criança;

- Favoreçam a imersão das crianças nas diferentes linguagens e o progressivo domínio por elas de vários gêneros e formas de expressão: gestual, verbal, plástica, dramática e musical;

Acolhendo todos os elementos até aqui abordados, (ensino de LE, Educação Infantil, dificuldades, benefícios, motivação, metodologias, atividades lúdicas e a importância de brincar e explorar) pode-se nos direcionar para a utilização da música como uma ferramenta lúdica possível para utilizar nas classes de LE com as crianças.

Segundo o Referencial Curricular Nacional para a Educação Infantil, a música é uma das muitas formas de linguagem, isso quer dizer que com ela as pessoas podem expressar e comunicar sentimentos, sensações e pensamentos (BRASIL, 1998). Ao conjecturar sobre estes aspectos, Guebert e Trautwien (2007) ressaltam que a música pode ser considerada um recurso didático, pois possibilita aos alunos a construção de pré-requisitos necessários para o desenvolvimento da compreensão, da linguagem oral e da futura escrita da criança. Além disso, é conceituada como um suporte no processo educativo, englobando todas as matérias da escola, pois fornece aos alunos a formação de hábitos, a memorização de conteúdos e a compreensão da função de diferentes linguagens existentes.

A música é um artifício acessível que se acomoda em todos os campos dos saberes e diferentes professores podem valer-se dela, sua utilização é recorrente nos cursos extraclasse, nas escolas e, evidentemente, na Educação Infantil, assim como destacam Bueno e Leal (2003). Seu uso está diretamente ligado com as ações de repetição e imitação, estratégias estas importantes para o ensino de LE. Com ela o professor tem a possibilidade de trabalhar tanto vocabulário como pronúncia, enriquecendo os dois, elevando o recurso da música como um instrumento auditivo e visual (quando dispõem de clipes) no conhecimento de uma nova 
língua. Além disso a música pode ser utilizada em várias brincadeiras, histórias e dramatizações sendo então uma ferramenta muito utilizada na EI.

Quando se analisa seu aspecto cognitivo, destaca-se que a música possui a capacidade de evocar e estimular uma série de reações fisiológicas que fazem a ligação direta entre o cérebro emocional e o cérebro executivo (MUSZKAT, 2014). Segundo o neurologista e neuropediatra Dr. Mauro Muszkat (2014), em uma recente matéria, a atividade musical mobiliza amplas áreas cerebrais, tanto as filogeneticamente mais novas (neocórtex) como os sistemas mais antigos e primitivos como o chamado cérebro reptiliano. Ou seja, a música não é apenas processada pelo cérebro, mas afeta seu funcionamento, a experiência musical modifica-o estruturalmente.

Refletindo sobre seu uso na educação, Muszkat (2014) alega que a música ativa vários circuitos neuronais, uma vez que seu processo demanda habilidades multimodais que envolvem a percepção de estímulos simultâneos e a integração de várias funções cognitivas como a atenção, a memória e das áreas de associação sensorial e corporal, que estão envolvidas tanto na linguagem corporal quanto na simbólica. Além disso, estudos afirmam que a exposição prolongada à música considerada prazerosa por seu ouvinte aumenta a produção de neurotrofinas, produzidas em nosso cérebro em situações de desafio. Estes elementos, principalmente as questões da memorização e da sensação de prazer frente a um desafio, proporcionados pelo emprego da música em sala de aula, parecem responder muito bem às questões antes levantadas sobre as dificuldades do ensino de LE, as metodologias e a motivação.

\section{Considerações finais}

Analisando as particularidades aqui levantadas quanto ao ensino de LE na Educação Infantil e confrontando-as com os resultados obtidos ao final do projeto proposto, certifica-se da possibilidade do uso da música, das brincadeiras, das histórias e de qualquer atividade lúdica como ferramenta didática para as aulas de língua estrangeira.

Pôde-se constatar no Centro Educacional Loni Emmendoerfer de Jaraguá do Sul, durante os anos letivos de 2014 e 2015 que as aulas de LE na Educação Infantil com o enfoque lúdico teve respostas muito positivas. As aulas atenderam cento e setenta crianças aproximadamente entre um e seis anos. Foi possível perceber que as crianças assimilaram o novo idioma sem a necessidade de tradução, o que torna o aprendizado mais eficaz. Através das brincadeiras, jogos, músicas e outras atividades lúdicas as crianças compreenderam o idioma naturalmente, reproduzindo-os até mesmo em casa, o que muitos pais relataram. As canções que eram cantadas na escola os alunos tentavam cantar para os pais, por exemplo, e muitas vezes a professora era abordada por eles porque não entendiam muito bem o que as crianças cantavam em casa. Depois de saber qual a música que as crianças estavam cantando na escola até os pais entravam na brincadeira em casa e cantavam com os filhos.

Sendo a música uma forma de linguagem, com seu uso tem-se a possibilidade de aprimorar e melhora-se a expressão pessoal e a comunicação de fatores impalpáveis. Pode-se encarar este recurso como uma valia no processo educativo e, da mesma forma, uma 
ferramenta lúdica na aquisição de uma nova língua, principal interesse da prática de professores de língua estrangeira.

O contato com a LE, que frequentemente se dá por forma extracurricular, deve estimular prazer, interesse e motivação nos alunos. Os alunos de Educação Infantil vivenciam uma etapa muito importante e rica de seus desenvolvimentos pessoais, dessa forma se faz necessário levar para as aulas de LE o que lhes é primordial nesta fase: brincar. É através da brincadeira que a criança explora e experimenta o mundo, conhece a si e a seu grupo. Existe a possibilidade de aprender brincado, isso se revela nas ações lúdicas com as crianças, as aulas devem lançar mão de músicas, acompanhadas ou não de gestos, jogos e brincadeiras.

Para concluir este estudo, pode-se dizer que o uso das atividades lúdicas no ensino de LE na Educação Infantil é legítimo, contudo o professor deve ser cuidadoso no momento da sua seleção, bem como na apresentação aos alunos. Além disso, consideramos como um bom aproveitamento desta ferramenta de ensino, a maneira através da qual o professor apresentará a atividade e a conduzirá em sala de aula. Enfim, o interesse e participação dos alunos de EI aliados à sua criatividade, extremamente exigida neste nível de ensino, garantem ao professor uma utilização consciente, prazerosa e proveitosa das atividades lúdicas na sala de aula de LE.

\section{REFERÊNCIAS}

BRASIL. Referencial curricular nacional para a educação infantil. Brasília: Ministério da Educação e do Desporto, Secretaria de Educação Fundamental, 1998.

BRASIL. Diretrizes Curriculares Nacionais para a Educação Infantil. Brasília: Ministério da Educação (MEC), Secretaria de Educação Básica, 2010.

BUENO, Jayme Ferreira; LEAL, Maria Rute. O ensino e a aprendizagem de uma língua estrangeira. Revista Educação em Movimento, Curitiba, v.2, n.6, p.45-56, set./dez.2003.

\section{GUEBERT, Mirian C. Castellain; TRAUTWEIN, Mariana Medeiros. O ensino da língua estrangeira na educação infantil. Educere. PUCPR, Curitiba, 2007}

MUSZKAT, Mauro. Música, neurociência e desenvolvimento humano. Biblioteca Virtual da Antroposofia. Disponível em: http://www.antroposofy.com.br/wordpress/musicaneurociencia-e-desenvolvimento-humano/. Acesso em: 22 nov. 2014.

ROSIN, Alessandra Ferreira; TINOCO, Bruno César Barbosa. O uso da música no ensino de língua estrangeira. UFRJ, Rio de Janeiro, 1998 